\title{
Making Hospitals Less Toxic: Safer Pest Control
}

Hospitals, for good reason, have a great interest in maintaining a clean environment, free of infectious agents and pests. At the same time, hospitals have an ethical duty to do no harm that must extend to the impacts of the pesticides and cleaning agents they use on their patients, staff and the environment. This is especially the case in hospitals because some of their patients may be particularly vulnerable (by virtue of medical condition or age) to the effects of what are, after all, products specifically designed to harm or kill living organisms. Thus, hospitals need to use the least environmentally and occupationally harmful products that will do the job, while also looking at the cost implications of the choices that are made. In this article, I discuss pesticides, and in my next column, I will discuss "green" cleaners.

A recent study on pesticide use in the U.S. carried out by Health Care Without Harm and Beyond Pesticides surveyed the top 171 U.S. hospitals (Owens 2003). Of the 22 responding hospitals:

- $100 \%$ use chemical pesticide products either on their grounds, inside the buildings or both.

- $91 \%$ use chemical pesticide indoors and $77 \%$ use chemical pesticides outdoors.

- $73 \%$ hire a pest control company to manage the majority of the hospital's structural pest management program.

- $41 \%$ hire a pest control company to manage the majority of the hospital's grounds.

Of particular concern is the finding that:

- $36 \%$ use pesticide products that are no longer registered for use by the U.S. Environmental Protection Agency (EPA).

- $18 \%$ use a pesticide product in which the active ingredient is being phased out by EPA due to the unacceptable risk associated with its use.

In short, the author concludes, “ ... it appears that the majority of U.S. hospitals have an urgent need to adopt safer pest management practices. Implementation of cost-effective IPM programs can eliminate the unnecessary use of hazardous pesticides that threaten the health of patients and staff."

There is no reason to believe that the situation is markedly different in Canada. Yet safe and effective alternatives exist, although they need to be tailored to the unique situation of each setting. The U.S. study notes that pest control begins with good housekeeping and sanitation practices, including better storage of fruit, foods and waste, while sealing cracks and other entry points to reduce access; this can reduce flies (including fruit flies), cockroaches, ants and rodents. Eliminating leaks and moisture and removing clutter and harbourage can also make the environment less appealing to pests. In addition, flypaper, UV light traps indoors and traps with non-toxic attractants outdoors are effective for fly control. Glue-boards, pheromone traps and the use of lowhazard, low-volatility baits, such as boric acid, are the next line of defence against cockroaches. Ground cayenne pepper at entry points, as well as snap traps, can help control rodents.

In addition to controlling pests in the hospital itself, attention needs to be paid to the use of pesticides in grounds maintenance, especially at a time when growing numbers of municipalities across Canada are moving to restrict or eliminate the cosmetic use of pesticides. Where better to set an example of healthy grounds maintenance than the local hospital? Numerous municipal and private sector organizations have reduced or even eliminated the use of pesticides through a combination of horticultural, biological and nonchemical control options. Some hospitals are adopting the same approach.

The overall approach, one that is recommended by many experts, including the U.S. study described earlier, is known as Integrated Pest Management, or IPM. Thus, the U.S. report found that:

- $73 \%$ of the 22 hospitals report using an IPM approach to pest management.

- $45 \%$ use one or more pesticide products containing boric acid, a least-hazardous pesticide.

- $14 \%$ post notification signs for both indoor and outdoor pesticide applications.

- $27 \%$ have provided pesticide-poisoning training for their staff.

The report goes on to list examples of U.S. hospitals that have used IPM, including veterans hospitals, the San Francisco General Hospital and Brigham and Women's Hospital. In an earlier report, Citizens' Environmental Coalition (2000) reports the following success stories:

- At least 10 Boston hospitals have been using IPM for 15 years; they no longer use rodenticides or pesticide sprays and do not make "preventive" pesticide applications.

- The University of Rochester Medical Centre has eliminated roach and ant aerosols, organophosphate insecticides and preventive applications in a hospital, ambulatory care centre, health science schools and 25 associated medical complexes. In the process, they have cut costs for materials and labour, while reducing the risks to patients, staff and the general public.

In Canada, St. Mary's Hospital, in Kitchener, Ontario (winner of the 2002 Green Health Care Award for Overall Leadership), has eliminated the use of chemicals; its landscaping company uses natural pest and weed control methods and has removed plants that were prone to insect attack. As part of its ongoing redevelopment, St. Mary's is developing a landscape plan that "will incorporate the use 
of drought-resistant native plants, ground cover and salt tolerant plants." The benefits are not only environmental: there are economic benefits, such as reduced liability with respect to those with sensitivities or allergies; there are social benefits such as improved community relations, public image and staff morale and success in implementing this and other environmental initiatives both at the hospital and at home. (The full case study is available at www.c2p2online.com/documents/StMarys-lawns.pdf.)

\section{Resources}

For a good set of resources and links, go to the Health Care Environet website (www.c2p2online.com/healthcare), where you will find a link to the site for responsible pest management (www.pestinfo.ca).

\section{References}

Citizens Environmental Coalition. 2000. Environmentally Safe Hospitals: Reducing Waste and Saving Money. New York: Citizens Environmental Coalition.

Owens, Kagan. 2003. Healthy Hospitals: Controlling Pests Without Harmful Pesticides. Washington DC: Heath Care Without Harm (also available at www.noharm.org/).

\section{About the Author}

Dr. Trevor Hancock is Healthcare Quarterly's environmental editor. He is a founder of the Canadian Coalition for Green Health Care and a founder and member of the Board of the Canadian Association of Physicians for the Environment.

\section{Recent Duracell television commercials claim}

\section{that: " $\mathbf{7}$ out of $\mathbf{1 0}$ hospitals trust Duracell}

more than any other brand of battery." Ever

wondered how they arrived at this conclusion?

Duracell hired an independent research company

(we checked) to conduct a survey of the

purchasing agents at a random sampling of

hospitals in the U.S. Among the results, the survey

indicated that almost three-quarters of

respondents indicated Duracell (on an unaided

basis) when asked which battery they trusted most for general use.

When purchasing batteries specifically for mobile telemetry heart monitors, 7 out of 10 respondents said they trusted Duracell more than any other brand.

Whoever said advertising was only creative!

\section{HayGroup}

Transforming health care organizations through a focus on strategy, people, work and performance:

- Planning

- Operational Improvement

- Organizational Effectiveness

- Human Resources Management

- Reward Programs

Contact:

Mark Hundert

National Director

Tel: (416) 868-1371

Fax: (416) 868-0362
A unique strategy to eliminate cancer

A unique recruitment strategy for cancer prevention clinical trials has encouraged more than five married couples at increased risk for either breast or prostate cancer to enroll. Surgeons and physicians at Toronto Sunnybrook Regional Cancer Centre, the comprehensive cancer program at Sunnybrook \& Women's, have combined recruitment efforts for the study of tamoxifen and raloxifene (STAR) trial for breast cancer and the selenium and vitamin E cancer prevention trial (SELECT) for prostate cancer.

STAR, a North American breast cancer prevention trial, will compare the proven benefits of tamoxifen to the promising effects of raloxifene in postmenopausal women who are at increased risk of the disease. This is the largest breast cancer prevention study ever undertaken and will include 19,000 postmenopausal women at over 500 sites including the one at Sunnybrook \& Women's and those in other parts of Canada, the U.S. and Puerto Rico. The study is being conducted by the National Surgical Adjuvant Breast and Bowel Project, a not-for-profit cancer research group funded by the National Cancer Institute (NCI).

The study is open to men over 55 (over 50 if of African descent), who have never had prostate cancer and who are in generally good health. Patients are required to visit TSRCC every six months and screened for prostate cancer annually. This trial is on target to complete its enrollment phase in June 2004.

For more information on the trial, please contact the SELECT Clinical Research Coordinator at 416-480-6100 ext. 2890 or the STAR Clinical Research Coordinator at 416-323-7721 